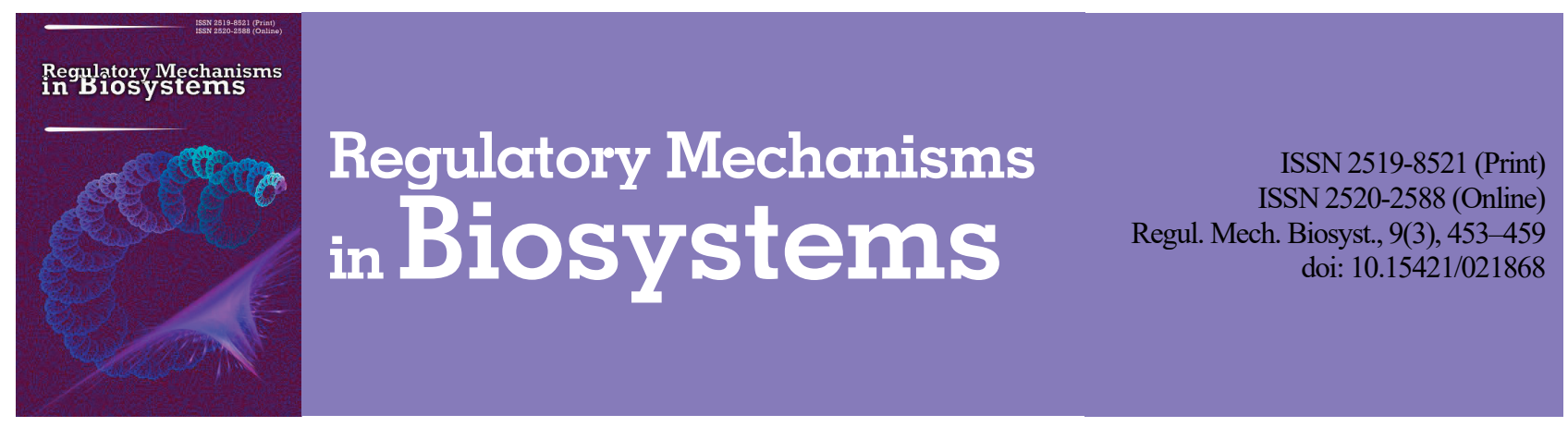

\title{
Influence of the type of autonomic tone on the volume of the mucous membrane of the small intestine of laying hens
}

\author{
A. Tybinka, H. Blishch, O. Shchebentovska \\ Stepan Gzhytskyi National University of Veterinary Medicine and Biotechnologies, Lviv, Ukraine
}

Article info

Received 03.06.2018

Received in revised form

14.07.2018

Accepted 19.07.2018

\begin{abstract}
Tybinka, A., Blishch, H., \& Shchebentovska, O. (2018). Influence of the type of autonomic tone on the volume of the mucous membrane of the small intestine of laying hens. Regulatory Mechanisms in Biosystems, 9(3), 453-459. doi:10.15421/021868
\end{abstract}

Stepan Gzhytskyi National

University of Veterinary

Medicine and

Biotechnologies,

Pekarska st., 50

Lviv, 79010, Ukraine.

Tel.: + 38-067-353-03-20

E-mail:

a.m.tybinka@gmail.com

The connection between the separate structural parts of the mucous membrane of the small intestine of laying hens and the typological features of the autonomic tone were investigated. The studies were conducted on adult chickens of the cross-breed "IsaBrown", which were divided into two groups: sympathicotonic chickens and sympathico-normotonic chickens, by the methods of electrocardiography and variation-pulsometry research. In the small intestine of the poultry of each group, the linear dimensions were determined first, and then the volume of the entire mucous membrane and its separate parts (villi, crypt, muscular plate), as well as the volume of connective tissue fibers in the crypt region. Research has shown that the villi account for $3 / 4$ of the volume of the entire mucous membrane. The volume of villi in the entire small intestine is more important in sympathico-normotonic chickens. This same poultry group has an advantage in the indicators of the volume of the muscular plate, but only in the duodenum and jejunum. In indicators of crypt volume, it turned out to be quite the opposite of the relationship with the typology of autonomous influences. In all studied intestines, the higher values of this indicator belong to the sympathotonic chickens. However, in terms of the volume of the entire mucous membrane, larger values still correspond to sympathico-normotonic chickens. Sympathicotonic chickens are inferior to them in the duodenum - at $1,005 \mathrm{~mm}^{3}$, in the jejunum - at $2,699 \mathrm{~mm}^{3}$ and in the ileum - only $78 \mathrm{~mm}^{3}$. Investigating the structure of the villi, we established that the volume of their epithelium in all three sections of the small intestine has higher values in the sympathico-normotonic chickens, and the larger volume of the lamina propria of the villi in the sympathicotonic chickens. At the same time, the connection with the type of autonomic tone is reflected in the ratio between the two layers of villi. In all three sections of the small intestine of sympathicotonic chickens, the ratio between the epithelium and the lamina propria was, on average, $65 \% / 35 \%$, or $2 / 1$. In sympathico-normotonic chickens, this ratio varied and, on average, equalled $75 \% / 25 \%$, or $3 / 1$. The increase in the tone of sympathetic centers contributes to the growth of volume both as the total amount of fibers of connective tissue, and also as separate elastic fibers in the area of crypt. According to the data,indicators of the sympathico-normotonic chickens are inferior to those of sympathicotonic chickens in all of the small intestine. It was also found that in both groups of poultry the volume of elastic fibers was approximately half the volume of all fibers of the connective tissue of the duodenum. In other sections of the small intestine, this figure was reduced to about $1 \frac{1}{3}$. Consequently, the typological features of the autonomic tone, providing various trophic-regulatory effects on the mucous membrane of the small intestine, cause the formation of differences in its volume.

Keywords: small intestine of chickens; sympathicotonic chickens; sympathico-normotonic chickens; volume of villi; volume of connective tissue fibers.

\section{Introduction}

The mucous membrane of the intestine of birds, similarly to other types of animals, is an active structure which is closely connected to other membranes and in the condition of dynamic balance. It constantly adapts to variable conditions of internal and especially external media. The most intensive changes in the structure of the intestine certainly take place during the embryonic period, when at the beginning, cellulartissue components form, which unite into a morphological-functional composition (Shyer et al., 2013; Wali \& Kadhim, 2014; Lilburn \& Loeffler, 2015). Therefore, by the time a bird hatches, the intestine as well as most of the digestive organs is sufficiently formed according to the main indicators of structure and chemical composition, so chickens can consume food on their own (Sklan, 2001; Uni et al., 2003; China et al., 2017). Morphological changes in the structure of the mucous membrane in the postnatal period of ontogenesis are significantly related to genetic factors (Forder et al., 2012; Khalid et al., 2014; Mabelebele et al., 2014; Okpe et al., 2016), and characteristics of diet consumed by poultry in different periods of their life. This especially manifests in commercial poultry whose diet as they grow to a certain age is changed in accordance with technology of their rearing (Laudadio et al., 2012; Nasrin et al., 2012; Sittiya \& Yamauchi, 2014). Changes in the structure of the mucous membrane also take place when birds feed during intensely or experience hunger (Incharoen et al., 2010), are subject to manipulations (Yamauchi et al., 2010) involving addition of medical preparations of feed additives to their diet (Wijtten et al., 2012; Tsirtsikos et al., 2012; Incharoen, 2013; Cheled-Shoval et al., 2014) and stress situations (Varasteh et al., 2015; Marchini et al., 2016). At the same time, excessive impacts on the intestinal wall can cause pathological processes instead of adaptive reactions (Heak et al., 2017; Wang et al., 2018). A significant parameter for determining the efficiency of the digestive organs is the age formation of the nervous system (Goldstein \& Nagy, 2008; Heanue et al., 2016; Chevalier et al., 2017). Without the regulatory action of the autonomic nervous system, the activity of the intestinal wall is observed to have a certain chaotic character. Therefore, the functioning of the intestinal epithelium of chickens before the formation of submucous plexus is characterized by an undetermined polyphase pattern. After the plexus is activated, the 
functioning of the epithelium of 17-18 day old fetuses obtains rhythmicity in the form of two-phase daily rhythms (maximum - night, minimum - day) (Sokolov \& Chukalovskaja, 1980; Aubert et al., 2004). The submucous plexus of the intestine is structurally and functionally related to other plexuses of the intestinal wall (intramuscular, mucous and subserous) and all of them together form the complex nervous system of the intestine (Hao et al., 2016; Uesaka et al., 2016). The basis of the submucous plexus is composed mostly of bunches of unmyelinated nerve fibers which form large loops and contain small clusters with a small amount of nerve cells (up to ten neurons). Also, one can find average-sized single clusters of nerve fibers with a few dozen cells. Also, the mucous plexus contains thinner bunches of nerve fibers, which form smaller loops. In general, the mucous plexus can be conditionally divided into two parts: nervous plexus of villi and nervous plexus of crypts (Ali \& McLelland, 1978; Fekete \& Csoknya, 1987; Doyle et al., 2004). However, in general, all neurons of the intestine can be united into two groups: mobile and sensitive, though according to ultrastructural, hystochemical, biochemical and pharmaceutical properties of these neurons, ten or even more different types are distinguished (Furness \& Costa, 1980; Furness, 2000; Yang et al., 2013). During ontogenesis, all nerve cells of the intestinal wall derive from the cells of neural crests (Sasselli et al., 2012). Therefore, in the process of age formation of the autonomic nervous system and establishment of its functional properties, the regulatory impacts on all organs modify, leading to their structural adaptation. Total tone of sympathetic and parasympathetic centers has an important role in this process. We have found very few studies in the scientific literature which examine the influence of this tone on the morphology of particular organs of animals (Kononenko \& Zaitsev, 2009), including the intestine of chickens (Tybinka et al., 2016). At the same time, we found no literature data on the relationship between the typological peculiarities of the tone of autonomic nervous system and the parameters of volume of separate layers and the entire mucous membrane of chickens. Thus, we focused our study on these parameters.

\section{Materials and methods}

For the study, we selected a group of clinically healthy 1 year old ISA Brown cross chickens, which were reared in a poultry farm. Using electrocardiographic and variation-pulsometric examination (Baevskij et al., 1984), we determined the peculiarities of the muscular tone of the autonomic nervous system for each of the birds. Using the results of this examination, the poultry were divided into two groups. The first group consisted of 16 chickens with high clearly manifested sympathetic tone sympathicotonic chickens (ST). The second group was formed of 17 chickens, the autonomous tone of which was characterized by deviation from the manifested sympathicotonia towards normotonia - sympathico-normotonic chickens (ST-NT). After euthanasing the birds, the small intestine was extracted and divided into its separate sections (duodenum, jejunum and ileum). For each of them, we determined length and perimeter (circular length), and also selected samples of the intestinal wall, which were fixated in Bouin's solution and then processed into paraffinised sections. For total detection of connective tissue fibers, histosections were stained using the methods of Van Gieson and Pacini (Mulisch \& Welsch, 2010), and also for separate detection of elastic fibers only, we performed staining according to Weigert (Mulisch \& Welsch, 2010). Using the prepared histopreparations and the method of computer morphometry, we analyzed the thickness of both the entire mucous membrane and its separate layers (muscular panel, crypt and villi). Taking into account the obtained parameters, we calculated the volume of the entire mucous membrane and its particular layers. In the villi, using the ratio of epithelium and lamina propria, we determined the volumes of these structures. Also, in the area of crypts, first we determined the percentage content, and then, on its basis, we calculated the volume of the fibers of the connective tissue. For statistical analysis of the study results, we used StatPlus 2008 program. Comparison of mean values of these groups was made on the basis of Student's t-criterion. Digital material in the tables and text is presented in the following form: $\mathrm{x} \pm \mathrm{SE}$, where $\mathrm{x}$ - sample mean, $\mathrm{SE}$ - standard error of average value.

\section{Results}

Having conducted a complex of planned morphometric research, we found that the results are characterized by a certain dependence on the type of the total tone of the autonomous centers. High sympathetic tone of ST-chickens caused higher values of the perimeter of the jejunum and ileum and the length of duodenum. Increase in parasympathetic tone of ST-NT chickens led to formation of higher parameters of perimeter of the duodenum and length of the jejunum and ileum. The presented patterns indicate compensatory relationships between these two parameters, when greater length of intestine corresponds to its lower perimeter. This indicates the peculiarities of formations of sizes of the intestine in relation to tone-trophic influence caused by the autonomic nervous system. Similar patterns are also typical for separate membranes of the intestinal wall (mucous and muscular), and also other particular layers of these membranes. At the same time, in all studied intestinal sections, the height of the villi and thickness of the lamina propriae were higher among the sympathico-normotonic chickens. At the same time, sympathicotonic chickens showed higher parameters of crypt depth and thickness of the epithelium of the villi. Chickens of this group were characterized by higher percentage content of the total number of connective tissue fibers, and also of elastic fibers separately. This again indicates formation of certain compensatory-adaptive relationships between certain parameters, but at the level of the mucous membrane. At the same time, all examined parameters, on the one hand, supplement one another and allow detailed analysis of particular aspects of the regulatory mechanisms of the autonomic nervous system. However, on the other hand, higher values of these parameters among different groups of chickens complicates the formation of the general characteristic of the impact of different tone of the autonomous centers on the intestinal wall on the whole and the mucous membrane in particular. Nevertheless, in general, all mentioned peculiarities are orientated towards provision of optimum parameters of digestion during corresponding type of the autonomic tone.

Therefore, we calculated more complex parameters based on the previous data and characterized the volume of the entire mucous membrane and its layers in particular sections and in the entire small intestine (Table 1). Along with the absolute volume of certain layers, which was expressed in $\mathrm{mm}^{3}$, we also determined their percentage in the structure of mucous membrane, the volume of which was accepted as $100 \%$. Certainly, the determining impact on the parameters of volume in differrent sections depends on the length of these sections. Therefore, the largest volumes of different layers of the mucous membrane were in the jejunum, these parameters were 3-4 times lower in the duodenum and 1.52.0 times lower in the ileum. However, thickness of these layers also makes adjustments to the parameters of volume.

The smallest part of mucous membrane is its lamina propriae. Along the small intestine, the dependence of its volume on the typology of autonomic tone is not of the same type. Over most of the area of the small intestine, the volume of the lamina propriae was higher among STNT chickens (Table 1). In the duodenum, their prevalence over the other poultry group was $10.1 \mathrm{~mm}^{3}$, and $65.6 \mathrm{~mm}^{3}$ in the jejunum. Only in the ileum were the parameters of both groups almost equalized and minimum domination $\left(3.3 \mathrm{~mm}^{3}\right)$ of sympaticotonic chickens was observed. However, the mean parameter of the three sections was higher by $24.2 \mathrm{~mm}^{3}$ among sympatico-normotonic chickens. A similar situation was also observed with total volume of lamina propriae of the entire small intestine. There, the prevalence of the second group of birds over the first one increased to $72.4 \mathrm{~mm}^{3}$.

As for the percentage of the studied parameter within the entire mucous membrane, it was approximately the same in both groups of birds. However, in all sections of the small intestine, the ST-chickens had the minimum prevalence. This indicates higher dependence of the lamina propriae in the process of digestion during heightened tone of the sympathetic centers. Another interesting fact is the gradual two-fold increase in the share of lamina propriae in the volume of mucous membrane along the intestine. This process does not manifest a relationship with the typology of autonomous impacts and was observed in both groups. 
Table 1

Absolute and relative parameters of volume of particular layers of mucous membrane of chickens' intestine $(\mathrm{x} \pm \mathrm{SD})$

\begin{tabular}{|c|c|c|c|c|}
\hline Part of intestine & $\begin{array}{l}\text { Type of } \\
\text { ANS }\end{array}$ & $\begin{array}{c}\text { Volume of lamina propriae in } \mathrm{mm}^{3} \\
\text { (\% of volume of entire mucous membrane) }\end{array}$ & $\begin{array}{l}\text { Volume of crypts, } \mathrm{mm}^{3} \text { (\% of volume } \\
\text { of entire mucous membrane) }\end{array}$ & $\begin{array}{c}\text { Volume of villi, } \mathrm{mm}^{3} \text { (\% of volume } \\
\text { of entire mucous membrane) }\end{array}$ \\
\hline \multirow{2}{*}{ Duodenum } & ST & $246 \pm 21(2.8 \%)$ & $1,919 \pm 128(21.9 \%)$ & $6,598 \pm 244$ (75.3\%) \\
\hline & ST-NT & $257 \pm 28(2.6 \%)$ & $1,765 \pm 115(18.1 \%)$ & $7,748 \pm 269 * *(79.3 \%)$ \\
\hline \multirow{2}{*}{ Jejunum } & ST & $1,066 \pm 92(4.2 \%)$ & $5,428 \pm 249(21.4 \%)$ & $18,923 \pm 305(74.4 \%)$ \\
\hline & ST-NT & $1,131 \pm 116(4.0 \%)$ & $4,392 \pm 221 * * *(15.6 \%)$ & $22,593 \pm 297 * * *(80.4 \%)$ \\
\hline \multirow{2}{*}{ Ileum } & ST & $218 \pm 19(5.7 \%)$ & $914 \pm 65(23.9 \%)$ & $2,688 \pm 128(70.4 \%)$ \\
\hline & ST-NT & $215 \pm 19(5.5 \%)$ & $690 \pm 55^{*}(17.7 \%)$ & $2,994 \pm 149 *(76.8 \%)$ \\
\hline Mean parameter & ST & $510 \pm 42(4.0 \%)$ & $2,754 \pm 128$ (21.7\%) & $9,403 \pm 294$ (74.3\%) \\
\hline of three sections & ST-NT & $534 \pm 38(3.8 \%)$ & $2,282 \pm 112 * *(16.4 \%)$ & $11,112 \pm 329 *(79.8 \%)$ \\
\hline Total parameter & ST & $1,530 \pm 123(4.0 \%)$ & $8,262 \pm 313(21.7 \%)$ & $28,208 \pm 374$ (74.3\%) \\
\hline for small intestine & ST-NT & $1,603 \pm 115(3.8 \%)$ & $6,847 \pm 276^{* * *}(16.4 \%)$ & $33,335 \pm 407 *(79.8 \%)$ \\
\hline
\end{tabular}

Notes: $*-\mathrm{P}<0.05$, ** $-\mathrm{P}<0.01, * * *-\mathrm{P}<0.001$

A similar relationship with the type of autonomic muscular tone is also a characteristic of the volume of villi of the mucous membrane. However, unlike the volume of the lamina propriae, greater values of this parameter among sympatico-normotonics were found not only in the duodenum and jejunum, but over the entire small intestine. At the same time, their domination over sympathicotonic chickens was proportional to the length of the intestine, i.e. it was highest in the jejunum $3,670 \mathrm{~mm}^{3}(\mathrm{P}<0.001)$, intermediate in the duodenum $\left(1,150 \mathrm{~mm}^{3}, \mathrm{P}<\right.$ 0.01 ) and the lowest in the ileum $\left(306 \mathrm{~mm}^{3}, \mathrm{P}<0.05\right)$. The mean value of villi volume in these three small intestine sections of sympathicotonic chickens was lower compared to sympathico-normotonic chickens by $1,709 \mathrm{~mm}^{3}(\mathrm{P}<0.05)$. Also, the total volume of villi of the mucous membrane of the entire small intestine of ST chickens and ST-NT chickens differed far more significantly and equaled $5,126 \mathrm{~mm}^{3}(\mathrm{P}<0.05)$.

Characterising the percentage content of the villi in the volume of mucous membrane of the small intestine revealed that the villi account for $3 / 4$ of the total volume. The minimum share of villi was found in the ileum of ST chickens (70.4\%), and the maximum in the jejunum of STNT chickens $(80.4 \%)$. The dependence of this parameter on the type of autonomic tone is close to the absolute parameters expressed in $\mathrm{mm}^{3}$. Therefore, along the entire intestine, its higher values corresponded to the sympathico-normotonic chickens.

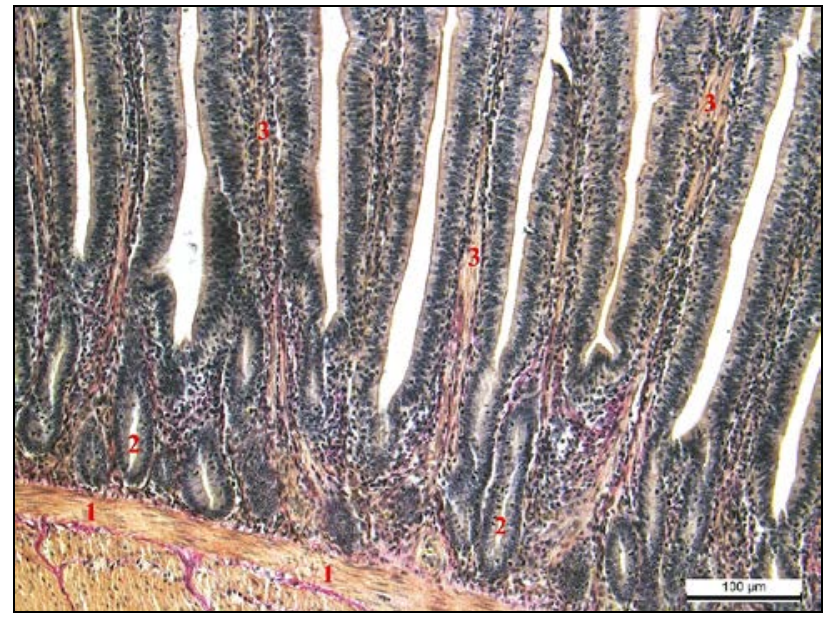

Fig. 1. Fragment of mucous membrane of the jejunum of a ST-NT chicken: lamina propriae of mucous membrane (1), crypts of mucous membrane (2), villi of mucous membrane (3); Van Gieson staining

A totally contrasting dependence on the typological peculiarities of autonomic impacts was seen in the volume of the crypts. Higher values of this parameter in all studied sections of the small intestine were observed among sympathicotonic chickens, they prevailed over sympathico-normotonic chickens by $155 \mathrm{~mm}^{3}$ - in the duodenum, and by $1,036 \mathrm{~mm}^{3}(\mathrm{P}<0.001)$ - in the jejunum and by $224 \mathrm{~mm}^{3}(\mathrm{P}<0.05)$ in the ileum. Therefore, the mean value of this parameter in the studied intestines of chickens of both groups differed by $472 \mathrm{~mm}^{3}(\mathrm{P}<0.01)$. However, the clearest dominance of the chickens of the first group over the birds of the second group was manifested in total parameters of volume of the crypts of the entire small intestine. At the same time, the difference between the ST and ST-NT chickens equaled $1,416 \mathrm{~mm}^{3}$ $(\mathrm{P}<0.001)$.

The percentage of crypts in the structure of the mucous membrane had no clear pattern in the studied groups of birds. Therefore, the ST chickens had intermediate values of the share of crypts in the duodenum, minimum in the jejunum, and maximum in the ileum. Also, sympathico-normotonic chickens were characterized by the highest share of crypts in the duodenum, the lowest in the jejunum and intermediate in the ileum.

The previously described parameters of volumes of the lamina propriae, crypts and villi together form the volume of the entire mucous membrane. Therefore, on the basis of these parameters alone, even without a morphometric examination of the entire mucous membrane, we can see that in the entire small intestine, the highest parameters of its volume correspond to sympathico-normotonic chickens. Further study fully proved this presumption. In the duodenum and jejunum, the dominance of the second group of chickens $(9,769 \pm 313$ and 28,116 \pm $462 \mathrm{~mm}^{3}$ respectively) over the first group (8,764 \pm 292 and 25,417 \pm $448 \mathrm{~mm}^{3}$ respectively) was quite significant and equaled 1,006 $(\mathrm{P}<0.05)$ and 2,699 $\mathrm{mm}^{3}(\mathrm{P}<0.01)$ respectively. This was conditioned by the larger sizes of these sections (especially the jejunum) and also the fact that ST-NT chickens had higher values of both volume of villi and lamina propriae. Also, by contrast, in small ileums higher values of volumes of lamina propriae and crypts were observed among ST chickens. For this reason, by the volume of mucous membrane of this section, the domination of chickens of the second group $\left(3,899 \pm 158 \mathrm{~mm}^{3}\right)$ over the chickens of the first group $\left(3,821 \pm 197 \mathrm{~mm}^{3}\right)$ manifested insignificantly and equaled only $78.4 \mathrm{~mm}^{3}$. However, by mean values of the volume of mucous membrane of the studied intestines, the domination of ST-NT chickens $\left(13,928 \pm 352 \mathrm{~mm}^{3}\right)$ over ST chickens $(12,667 \pm$ $\left.316 \mathrm{~mm}^{3}\right)$, remained quite significant $-1,261 \mathrm{~mm}^{3}(\mathrm{P}<0.05)$. Therefore, the largest difference between the groups of birds was observed in total values of the volume of the mucous membrane of the entire small intestine. By this parameter, ST chickens $\left(38,001 \pm 405 \mathrm{~mm}^{3}\right)$ were behind the ST-NT chickens $\left(41,784 \pm 437 \mathrm{~mm}^{3}\right)$ by $3,783 \mathrm{~mm}^{3}(\mathrm{P}<0.001)$.

Because the dominant part of the mucous membrane of the intestine is the villi, along with determination of their total volume, we also analyzed the volumes of particular layers of these villi - epithelium cover and the lamina propria. Similarly to previous parameters, along with absolute sizes expressed in $\mathrm{mm}^{3}$, we determined the percentage of each layer in the volume of villi (Table 2).

Morphometric examinations determined that in all three sections of the small intestine, the volume of epithelium of the villi had higher values among sympathico-normotonic chickens (Fig. 2). This group of birds dominated over the other group by $1,322 \mathrm{~mm}^{3}(\mathrm{P}<0.01)$ in the duodenum, by $3,997 \mathrm{~mm}^{3}(\mathrm{P}<0.05)$ in the jejunum and by $473 \mathrm{~mm}^{3}(\mathrm{P}<$ $0.05)$ in the ileum. At the same time, the mean parameter of differences between the groups of birds equaled 1,931 $\mathrm{mm}^{3}(\mathrm{P}<0.05)$. And usually, the largest difference between the parameters of ST and ST-NT chickens is formed by the parameter of total volume of epithelium of the entire small intestine $-5,793 \mathrm{~mm}^{3}(\mathrm{P}<0.01)$.

Unlike the previous parameter, higher values of the volume of the lamina propria of the villi, by contrast, correspond to sympathicotonic 
chickens. In the duodenum, the parameter of sympathico-normotonic chickens was lower by $172 \mathrm{~mm}^{3}$, by $327 \mathrm{~mm}^{3}$ in the jejunum, and by $167 \mathrm{~mm}^{3}$ in the ileum. Average volume of lamina propria of all three sections of the small intestine of chickens of the first and the second group differed by $222 \mathrm{~mm}^{3}$. The total volume of lamina propria in the entire intestine of ST and ST-NT chickens differed by $666 \mathrm{~mm}^{3}$.

The distinctive effect of typological peculiarities of the autonomic tone was observed in the percentage content of certain layers of villi. In all three small intestine sections of sympathicotonic chickens, the ratio of epithelium and lamina propria on average equaled $65 \%$ / 35\%, or $2 / 1$. In sympathico-normotonic chickens, this ratio on average equaled $75 \%$ / $25 \%$, or $3 / 1$. These proportions indicate the peculiarities of functional characteristics of villi of the small intestine in relation to the typology of effects of the autonomic nervous system. Also, the demonstrated results prove the higher activity of the epithelium layer compared to the lamina propria.

\section{Table 2}

Absolute and relative parameters of volume of structural parts of villi of mucous membrane of the intestine of chickens $(x \pm S E)$

\begin{tabular}{|c|c|c|c|}
\hline Part of intestine & $\begin{array}{l}\text { Type } \\
\text { of ANS }\end{array}$ & $\begin{array}{l}\text { Volume of epithelium } \\
\text { of villi, } \mathrm{mm}^{3} \text { (\% of the } \\
\text { total volume of villi) }\end{array}$ & $\begin{array}{c}\text { Volume of lamina propria } \\
\text { of villi, } \mathrm{mm}^{3} \text { (\% of the total } \\
\text { volume of villi) }\end{array}$ \\
\hline \multirow[b]{2}{*}{ Duodenum } & ST & $4,341 \pm 122(65.8 \%)$ & $2,256 \pm 71(34.2 \%)$ \\
\hline & ST-N & $5,663 \pm 165^{*+}(73.1 \%)$ & $2,084 \pm 66$ \\
\hline \multirow{2}{*}{ Jejunum } & ST & $13,037 \pm 409(68.9 \%)$ & $5,884 \pm 19$ \\
\hline & ST-NT & $17,035 \pm 395^{*}(75.4 \%)$ & $5,558 \pm 15$ \\
\hline \multirow{2}{*}{ Ileum } & ST & 1,76 & $924 \pm 57$ \\
\hline & ST-I & $(74.7 \%)$ & $757 \pm 44(25.3 \%)$ \\
\hline Mean & ST & $6,381 \pm 227(66.8 \%)$ & $3,022 \pm 187$ (33.2\%) \\
\hline for thr & ST-NT & $8,312 \pm 301^{*}(74.4 \%)$ & $2,799 \pm 152(25.6 \%)$ \\
\hline Total value & ST & $19,142 \pm 309(67.9 \%)$ & $9,065 \pm 339(32.1 \%)$ \\
\hline for small intestine & ST-NT & $24,935 \pm 347^{* *}(74.8 \%)$ & $8,399 \pm 295(25.2 \%)$ \\
\hline
\end{tabular}

Notes: * $-\mathrm{P}<0.05$, ** $-\mathrm{P}<0.01$, ***- $\mathrm{P}<0.001$.

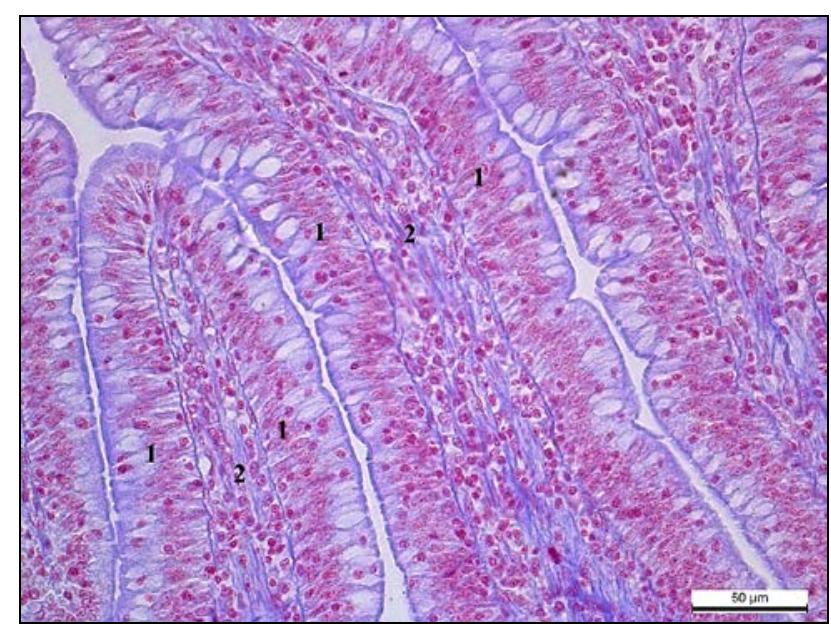

Fig. 2. Villi of the jejunum of a ST chicken: the epithelium of the villi (1), lamina propria of mucous membrane (2); Pacini staining

An important and integral part of the mucous membrane is its fiber connective tissue component. The examinations conducted prove that these fibers most densely localize in the area of crypts and their number is reliably affected by the type of autonomous tone (Table 3).

Analysis of the volume of total number of connective tissue fibers reveals that in all studied sections of the small intestine, sympathicotonic chickens showed higher values of this parameter (Fig. 3). In the duodenum, they prevailed over sympathico-normotonic chickens by $13 \mathrm{~mm}^{3}$, by $238 \mathrm{~mm}^{3}(\mathrm{P}<0.01)$ in the jejunum and by $42 \mathrm{~mm}^{3}(\mathrm{P}<0.001)$ in the ileum. It should be mentioned that in the latter section, the difference between the groups was the clearest in the percentage expression and equaled 39\%. The mean value of the three sections in ST and ST-NT chickens differed by $98 \mathrm{~mm}^{3}(\mathrm{P}<0.01)$, and the total volume of connective tissue fibers in the entire small intestine of chickens of the second group was $293 \mathrm{~mm}^{3}(\mathrm{P}<0.01)$ lower than in the first group. Along with the volume of the total number of connective tissue fibers in the crypt area, we performed a separate study of the volume of elastic fibers (Fig. 4). The data in Table 3 demonstrates that in both groups of birds, the volume of elastic fibers equals approximately half of the volume of all fibers of the duodenum connective tissue. In other sections, this parameter decreases approximately to $1 / 3$.

\section{Table 3}

Volume of connective tissue fibers in the area of crypts of mucous membrane of the intestine of chickens $(x \pm S E)$

\begin{tabular}{llcc}
\hline \multirow{2}{*}{ Section of intestine } & $\begin{array}{c}\text { Type of } \\
\text { ANS }\end{array}$ & $\begin{array}{c}\text { Volume of all connective } \\
\text { tissue fibers, } \mathrm{mm}^{3}\end{array}$ & $\begin{array}{c}\text { Volume of elastic } \\
\text { fibers, } \mathrm{mm}^{3}\end{array}$ \\
\hline \multirow{2}{*}{ Duodenum } & ST & $111.3 \pm 8.3$ & $56.6 \pm 3.4$ \\
& ST-NT & $98.6 \pm 7.6$ & $50.3 \pm 4.9$ \\
Jejunum & ST & $665.0 \pm 32.4$ & $224.7 \pm 17.7$ \\
& ST-NT & $426.9 \pm 28.7^{* *}$ & $167.8 \pm 12.2^{*}$ \\
Ileum & ST & $108.5 \pm 7.1$ & $30.5 \pm 1.9$ \\
Mean indicator & ST-NT & $66.5 \pm 4.8^{* * *}$ & $21.4 \pm 1.4^{*}$ \\
of three sections & ST & $295.0 \pm 20.7$ & $104.0 \pm 8.5$ \\
Total parameter & ST-NT & $197.3 \pm 15.9^{* *}$ & $79.8 \pm 4.8^{*}$ \\
of small intestine & ST-NT & $884.8 \pm 51.5$ & $311.9 \pm 23.6$ \\
\hline
\end{tabular}

Notes: $*-\mathrm{P}<0.05, * *-\mathrm{P}<0.01$, *** $-\mathrm{P}<0.001$.

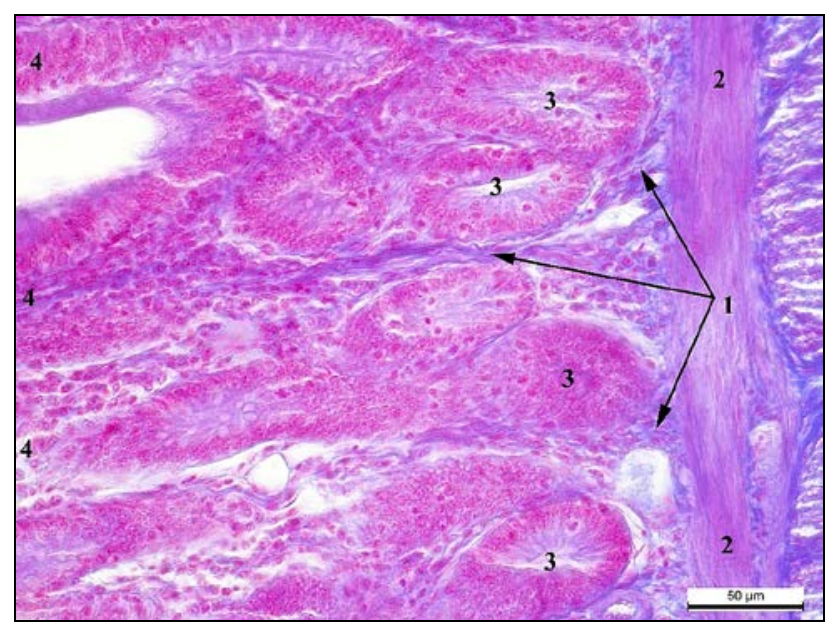

Fig. 3. The area of the crypts of ileum of a ST chicken: connective tissue fibers (1), lamina propria of mucous membrane (2), crypts (3), villi (4); Pacini staining

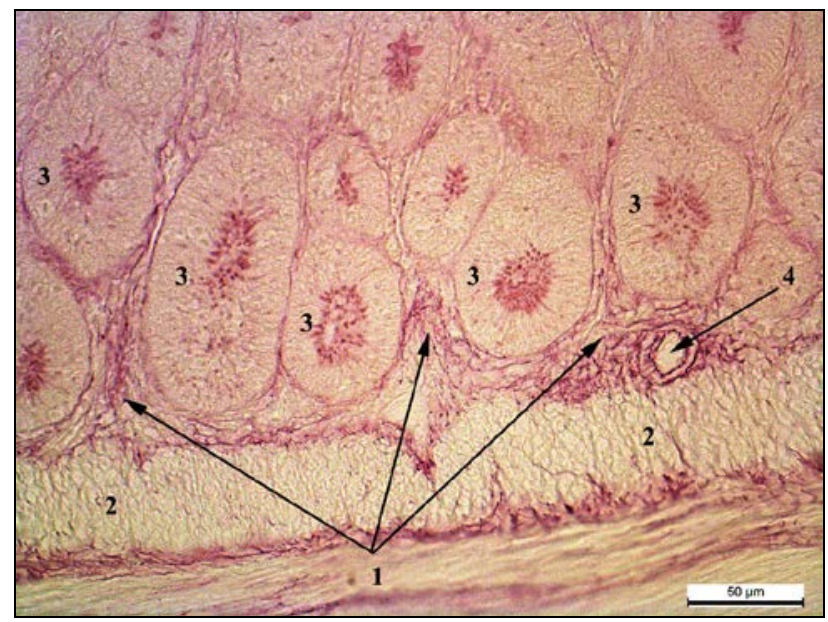

Fig. 4. The area of crypts of duodenum of a ST-NT chicken: elastic fibers (1), lamina propria of mucous membrane (2), crypts (3), blood vessel (4); Weigert staining

As for the relationship with the typology of autonomic tone, we observed full similarity with the previous parameter. I.e. along the entire small intestine, the sympathicotonic chickens were characterized by higher values of elastic fibers' volume. Therefore, these values were lower for sympathico-normotonic chickens by $6.3 \mathrm{~mm}^{3}-$ in the duodenum, by 
$56.9 \mathrm{~mm}^{3}(\mathrm{P}<0.05)$ - in the jejunum and by $9.1 \mathrm{~mm}^{3}(\mathrm{P}<0.05)-$ in the ileum. Mean values of this parameter in the studied intestines of both groups of chickens differed by $24.2 \mathrm{~mm}^{3}(\mathrm{P}<0.05)$. By total volume of elastic fibers in the entire small intestine, sympathicotonic chickens prevailed over sympathico-normotonic chickens by $72.4 \mathrm{~mm}^{3}(\mathrm{P}<0.01)$.

\section{Discussion}

Combination of structural components and functional peculiarities of each system of an organism occurs in such way that it provides the optimum conditions for the metabolic processes in it, achievement of maximum efficiency in performing its tasks and quick adaptation to varying conditions of internal and external media (Bahr, 2008; Taylor et al., 2014; Palmquist-Gomes et al., 2016). To achieve all goals at the same time, each morpho-functional system should be in a certain way flexible and adaptive to opportunities. This is possible through regulatory impacts of the endocrine system and the autonomic nervous system. At the same time, each of the systems is observed to have a clearly manifested specialization in regulating only a certain area of an organism's activity (Crossley \& Altimiras, 2000; Scanesa \& PierzchalaKoziec, 2014; Bedecarrats et al., 2016; Dennis, 2016).

One of the main distinctive features of the nervous system is its sensitivity, which manifests in the constant tone of the nerve centers. As we know, the sympathetic and parasympathetic sections of the autonomic nervous system are often characterized by antagonistic impacts on particular organs and systems of the organism. Decrease or increase of the tone in one of the sections causes an opposite effect in the same organ. Obviously, such fluctuations in tone are possible in both sections at the same time, therefore the final regulatory impact caused by the autonomic nervous system is determined by total tone of both sections. This leads to formation of a certain type of autonomic tone in animals' organisms, which is determined in the process of ontogenesis and conditions a complex of structural adaptations in all its systems (Shah et al., 2010; Kjaer \& Jorgensen, 2011; Tybinka et al., 2016; Sheng \& Zhu, 2018). Such adaptation reactions at different levels of structural organisation of an organism condition the formation of homeostasis both at these levels and in the entire organism. The studies of this state and determination of its quantitative equivalents result in formation of a parameter such as "norm". The total of such particular parameters form the general condition of an organism, which is called "health" (Jeurissen et al., 2002; Borell et al., 2007; Yegani \& Korver, 2008; Scanes, 2017).

The results of our studies indicate that in the intestinal wall of the small intestine of chickens, as in any typical morpho-functional system, self-regulating processes and adaptation to regulatory impacts take place. This is related to a certain type of autonomic tone. Depending on the functional tasks of each intestine in the digestion, the sizes of its structural units change, with the general structure of the intestinal wall remaining the same. Therefore, providing digestive process during different typology of autonomous impacts is characterized by different morphological orientation. At the same time, there are often seen compensatory phenomena in sizes of particular layers of the intestinal wall, when one group of birds has higher values of one parameter combined with lower values of another in all intestines. However, compensation is not full because each parameter is determined by a certain range of values. Greater depth and volume of crypts in sympathicotonic chickens cannot compensate for greater height and volume of villi in sympathico-normotonic chickens. This, finally, manifests in larger values of volume of mucous membrane of the entire intestine in sympathico-normotonic chickens. The morphometric analysis we conducted helps us understand the ways of formation of this advantage.

Also, it should be mentioned that dependence of particular structural elements of the intestinal wall on autonomous impacts is not uniform in its extent. This can be seen in the level of reliability between the values of particular parameters of chickens of the studied groups. For example, the impact of the type of autonomic tone on the parameters of epithelium volume is much more significant than on the volume of lamina propria. This is indicated by significant and reliable differences between the groups of birds in the first parameter, and relatively insignificant and not reliable differences in the second parameter. The pattern we found proves the significant role of the epithelium layer in the processes of adaptation of the intestinal wall to certain typology of autonomous impacts. Therefore, the values of lamina propriae in this process are much lower. Considering the determining role of epithelium in the processes of near wall digestion (Geyra et al., 2001; Esmail, 1988; Theerawatanasirikul et al., 2017), it is clear that change in sizes of epithelium layer will affect this process. According to the same principle, we can also see that the lamina propriae of the mucous membrane, compared to crypts and villi is less significant in the process of adaptation of the mucous membrane to the corresponding type of autonomic tone.

The described pattern and other results of studies demonstrate that efficient assessment of different morphological structures can be made only by taking into account their functional characteristics because even slight changes in the structure cause a certain change of function (Yamauchi, 2002; Lavin et al., 2008; Verdal et al., 2010).

An integrated part of the intestinal wall is connective tissue which, by forming interlayers between certain groups of cells or layers of other tissues, unites all these structures in an integrated morpho-functional composition. It also accumulates biologically active substances, immune cells (Casteleyn et al., 2010; Revajova et al., 2013), and blood vessels and nerves lie across it. Connective tissue in general and its fiber component in particular is a part of the trophic complex of a certain area (Zeng et al., 2003; Pandit et al., 2018). For this reason, connective tissue is considered to play an important role in formation of homeostasis (Borda-Molina et al., 2018; Kogut et al., 2018). The presence of reliable differences in the parameters of volume of connective tissue fibers in the studied groups of poultry, proves the important role of connective tissue in the processes of adaptation of the structure of the intestinal wall to peculiarities of regulatory impacts caused by the autonomic nervous system. At the same time, the stimulatory effect of sympathetic tone is clearly manifested on the volumes of both total number of connective tissue fibers and elastic fibers in particular.

A certain influence on the studied processes is caused by the area of the intestinal wall due to significant length of intestine, and also peculiarities of digestive processes in its particular parts (Uni et al., 1998; Yamauchi, 2007; Svihus, 2014). However, according to our results, the general tendency of the impact of the typology of autonomic tone on most parameters is similar over the entire length of the small intestine.

\section{Conclusions}

Formation of a particular type of autonomic tone in the organism of chickens conditions the corresponding pattern of tone-trophic influence on their intestine. This, finally, is reflected both in the linear parameters of the intestine and parameters of volume of its mucous membrane. The intensity of the relationship with the typology of autonomic tone is not the same for all layers of the mucous membrane, which indicates their different role in the processes of adaptation of the intestinal wall in general and the mucous membrane in particular to regulatory impacts caused by the autonomic nervous system. A certain increase in parasympathetic tone among sympathico-normotonic chickens provides higher values of villi volume, therefore of the entire mucous membrane, because villi are $3 / 4$ of its volume. High sympathetic tone in ST chickens conditions higher values of volume of all connective tissue fibers, and elastic fibers particularly. On the whole, all determined morphological peculiarities of the mucous membrane indicate its significant and differently orientated properties in the process of adaptation to the pattern of regulatory impacts caused by the autonomic nervous system.

\section{References}

Ali, H. A., \& McLelland, J. (1978). Avian enteric nerve plexuses. A histochemical study. Cell and Tissue Research, 189, 537-548.

Aubert, A. E., Beckers, F., Ramaekers, D., Verheyden, B., Leribaux, C., Aerts, J.-M., \& Berckmans, D. (2004). Heart rate and heart rate variability in chicken embryos at the end of incubation. Experimental Physiology, 89(2), 199-208.

Baevskij, R. M., Kirilov, O. I., \& Kleckin, S. Z. (1984). Matematicheskij analiz serdechnogo ritma pri stresse [Mathematical analysis of cardiac rhythm in stress]. Nauka, Moscow (in Russian). 
Bahr, J. M. (2008). The chicken as a model organism. Sourcebook of Models for Biomedical Research, 161-167.

Bedecarrats, G. Y., Baxter, M., \& Sparling, B. (2016). An updated model to describe the neuroendocrine control of reproduction in chickens. General and Comparative Endocrinology, 227, 58-63.

Borda-Molina, D., Seifert, J., \& Camarinha-Silva, A. (2018). Current perspectives of the chicken gastrointestinal tract and its microbiome. Computational and Structural Biotechnology Journal, 16, 131-139.

Borell, E., Langbein, J., Despres, G., Hansen, S., Leterrier, C., Marchant-Forde, J., Marchant-Forde, R., Minero, M., Mohr, E., Prunier, A., Valance, D., \& Veissier, I. (2007). Heart rate variability as a measure of autonomic regulation of cardiac activity for assessing stress and welfare in farm animals - A review. Physiology and Behavior, 92, 293-316.

Casteleyn, C., Doom, M., Lambrechts, E., Van den Broeck, W., Simoens, P., \& Cornillie, P. (2010). Locations of gut-associated lymphoid tissue in the 3month-old chicken: A review. Avian Pathology, 39(3), 143-150.

Cheled-Shoval, S. L., Withana Gamage, N. S., Amit-Romach, E., Forder, R., Marshal, J., Van Kessel, A., \& Uni, Z. (2014). Differences in intestinal mucin dynamics between germ-free and conventionally reared chickens after mannan-oligosaccharide supplementation. Poultry Science, 93, 636-644.

Chevalier, N. R., Fleury, V., Dufour, S., Proux-Gillardeaux, V., \& Asnacios, A. (2017). Emergence and development of gut motility in the chicken embryo. PLoS One, 12(2), e0172511.

China, A. M., Hill, D. R., Aurorac, M., \& Spencea, J. R. (2017). Morphogenesis and maturation of the embryonic and postnatal intestine. Seminars in Cell and Developmental Biology, 66, 81-93.

Crossley, D., \& Altimiras, J. (2000). Ontogeny of cholinergic and adrenergic cardiovascular regulation in the domestic chicken (Gallus gallus). American Journal of Physiology. Regulatory, Integrative and Comparative Physiology, 279, 1091-1098.

Dennis, R. L. (2016). Adrenergic and noradrenergic regulation of poultry behavior and production. Domestic Animal Endocrinology, 56, 94-100.

Doyle, A. M., Roberts, D. J., \& Goldstein, A. M. (2004). Enteric nervous system patterning in the avian hindgut. Developmental Dynamics, 229, 708-712.

Esmail, S. H. M. (1988). Scanning electron microscopy of intestinal villous structures and their putative relation to digestion and absorption in chickens. Reproduction Nutrition Development, 28(6A), 1479-1487.

Fekete, E., \& Csoknya, M. (1987). Fluorescence characterization of the nerve plexuses in the small intestine of the chicken. Acta Biologica Szegediensis, 33, 97-104.

Forder, R. E., Nattrass, G. S., Geier, M. S., Hughes, R. J., \& Hynd, P. I. (2012). Quantitative analyses of genes associated with mucin synthesis of broiler chickens with induced necrotic enteritis. Poultry Science, 91, 1335-1341.

Furness, J. B. (2000). Types of neurons in the enteric nervous system. Journal of the Autonomic Nervous System, 81(1-3), 87-96.

Furness, J. B., \& Costa, M. (1980). Types of nerves in the enteric nervous system. Commentaries in the Neurosciences, 235-252.

Geyra, A., Uni, Z., \& Sklan, D. (2001). Enterocyte dynamics and mucosal development in the posthatch chick. Poultry Science, 80(6), 776-782.

Goldstein, A. M., \& Nagy, N. (2008). A bird's eye view of enteric nervous system development: Lessons from the avian embryo. Pediatric Research, 64(4), 326-333.

Hao, M. M., Foong, J. P. P., Bornstein, J. C., Li, Z. L., Vanden Berghe, P., \& Boesmans, W. (2016). Enteric nervous system assembly. Functional integration within the developing gut. Developmental Biology, 417, 168-181.

Heak, C., Sukon, P., Kongpechr, S., Tengjaroenkul, B., \& Chuachan, K. (2017). Effect of direct-fed microbials on intestinal villus height in broiler chickens: A systematic review and meta-analysis of controlled trials. International Journal of Poultry Science, 16, 403-414.

Heanue, T. A., Shepherd, I. T., \& Burns, A. J. (2016). Enteric nervous system development in avian and zebrafish models. Developmental Biology, 417(2), 129-138.

Incharoen, T. (2013). Histological adaptations of the gastrointestinal tract of broilers fed diets containing insoluble fiber from rice hull meal. American Journal of Animal and Veterinary Sciences, 8(2), 79-88.

Incharoen, T., Yamauchi, K., Erikawa, T., \& Gotoh, H. (2010). Histology of intestinal villi and epithelial cells in chickens fed low-crude protein or low-crude fat diets. Italian Journal of Animal Science, 9(4), 429-434.

Jeurissen, S. H. M., Lewis, F., Klis, J. D., Mroz, Z., Rebel, J. M. J., \& Huurne, A. A. H. M. (2002). Parameters and techniques to determine intestinal health of poultry as constituted by immunity, integrity, and functionality. Current Issues in Intestinal Microbiology, 3, 1-14.

Khalid, K. K., Zuki, A. B., Noordin, M. M., Mohd, A. B., \& Mohd, Z. S. (2014). Light and scanning electron microscopy of the small intestine of young Malaysian village chicken and commercial broiler. Pertanika Journal of Tropical Agricultural Science, 37(1), 51-64.

Kjaer, J. B., \& Jorgensen, H. (2011). Heart rate variability in domestic chicken lines genetically selected on feather pecking behavior. Genes, Brain and Behavior, 10, 747-755.
Kogut, M. H., Genovese, K. J., Swaggerty, C. L., He, H., \& Broom, L. (2018). Inflammatory phenotypes in the intestine of poultry: Not all inflammation is created equal. Poultry Science, 97(7), 2339-2346.

Kononenko, V. S., \& Zaitsev, A. A. (2009). Analiz makromorfometrichnih parametriv sercja ovec' z riznim tonusom avtonomnih centriv [An analysis of macromorphometric parameters of heart of sheep with different tone of autonomous centers]. Naukovij Visnik L'vivs'kogo Nacional'nogo Universitetu Veterinarnoji medicini ta biotehnologij imeni S. Z. Gzhic'kogo, 11(2), 165-169 (in Ukrainian).

Laudadio, V., Passantino, L., Perillo, A., Lopresti, G., Passantino, A., Khan, R. U., \& Tufarelli, V. (2012). Productive performance and histological features of intestinal mucosa of broiler chickens fed different dietary protein levels. Poultry Science, 91, 265-270.

Lavin, S. R., Karasov, W. H., Ives, A. R., Middleton, K. M., \& Garland, T. Jr. (2008) Morphometrics of the avian small intestine compared with that of nonflying mammals: A phylogenetic approach. Physiological and Biochemical Zoology, 81(5), 526-550.

Lilburn, M. S., \& Loeffler, S. (2015). Early intestinal growth and development in poultry. Poultry Science, 94, 1569-1576.

Mabelebele, M., Alabi, O. J., Ng’ambi, J. W., Norris, D., \& Ginindza, M. M. (2014). Comparison of gastrointestinal tracts and $\mathrm{pH}$ values of digestive organs of Ross 308 broiler and indigenous venda chickens fed the same diet. Asian Journal of Animal and Veterinary Advances, 9(1), 71-76.

Marchini, C. F. P., Cafe, M. B, Araujo, E. G., \& Nascimento, M. R. B. M. (2016) Physiology, cell dynamics of small intestinal mucosa, and performance of broiler chickens under heat stress: A review. Revista Colombiana de Ciencias Pecuarias, 29, 159-168.

Mulisch, M., \& Welsch, U. (2010). Mikroskopische technik. Spektrum Akademischer Verlag.

Nasrin, M., Siddiqi, M. N. H., Masum, M. A., \& Wares, M. A. (2012). Gross and histological studies of digestive tract of broilers during postnatal growth and development. Journal of the Bangladesh Agricultural University, 10(1), 69-77.

Okpe, C. G., Abiaezute, N. C., \& Adigwe, A. (2016). Evaluation of the morphological adaptations of the small intestine of the African pied crow (Corvus albus). The Journal of Basic and Applied Zoology, 75, 54-60.

Palmquist-Gomes, P., Guadix, J. A., \& Perez-Pomares, J. M. (2016). A chick embryo cryoinjury model for the study of embryonic organ development and repair. Differentiation, 91(4-5), 72-77.

Pandit, K., Dhote, B. S., Mahanta, D., Sathapathy, S., Tamilselvan, S., Mrigesh, M., \& Mishra, S. (2018). Histological, histomorphometrical and histochemical studies on the large intestine of Uttara Fowl. International Journal of Current Microbiology and Applied Sciences, 7(3), 1477-1491.

Revajova, V., Slaminkova, Z., Gresakova, L., \& Levkut, M. (2013). Duodenal morphology and immune responses of broiler chickens fed low doses of deoxynivalenol. Acta Veterinaria Brno, 82, 337-342.

Sasselli, V., Pachnis, V., \& Burns, A. J. (2012). The enteric nervous system. Developmental Biology, 366, 64-73.

Scanes, C. G. (2017). Grand and less grand challenges in avian physiology. Frontiers in Physiology, 222, 1-5.

Scanesa, C. G., \& Pierzchala-Koziec, K. (2014). Biology of the gastro-intestinal tract in poultry. Avian Biology Research, 7(4), 193-222.

Shah, R., Greyner, H., \& Dzialowski, E. M. (2010). Autonomic control of heart rate and its variability during normoxia and hypoxia in emu (Dromaius novaehollandiae) hatchlings. Poultry Science, 89(1), 135-144.

Sheng, Y., \& Zhu, L. (2018). The crosstalk between autonomic nervous system and blood vessels. International Journal of Physiology, Pathophysiology and Pharmacology, 10(1), 17-28.

Shyer, A. E., Tallinen, T., Nerurkar, N. L., Wei, Z., Gil, E. S., Kaplan, D. L., Tabin, C. J., \& Mahadevan, L. (2013). Villification: How the gut gets its villi. Science, 342, 212-218.

Sittiya, J., \& Yamauchi, K. (2014). Growth performance and histological intestinal alterations of sanuki cochin chickens fed diets diluted with untreated wholegrain paddy rice. The Journal of Poultry Science, 51(1), 52-57.

Sklan, D. (2001). Development of the digestive tract of poultry. World's Poultry Science Journal, 57, 415-428.

Sokolov, V. I., \& Chukalovskaja, R. N. (1980). Proliferativnye processy i citohimicheskie osobennosti kishechnogo jepitelija cypljat [Proliferative processes and cytochemical features of the intestinal epithelium of chickens]. Morphology of farm animals. Collection of Scientific Papers, 60, 74-78 (in Russian).

Svihus, B. (2014). Function of the digestive system. The Journal of Applied Poultry Research, 23(2), 306-314

Taylor, E. W., Leite, C. A. C., Sartori, M. R., Wang, T., Abe, A. S., \& Crossley, D. A. (2014). The phylogeny and ontogeny of autonomic control of the heart and cardiorespiratory interactions in vertebrates. The Journal of Experimental Biology, 217, 690-703.

Theerawatanasirikul, S., Koomkrong, N., Kayan, A., \& Boonkaewwan, C. (2017). Intestinal barrier and mucosal immunity in broilers, Thai Betong, and native 
Thai Praduhangdum chickens. Turkish Journal of Veterinary and Animal Sciences, 41, 357-364.

Tsirtsikos, P., Fegeros, K., Balaskas, C., Kominakis, A., \& Mountzouris, K. C. (2012). Dietary probiotic inclusion level modulates intestinal mucin composition and mucosal morphology in broilers. Poultry Science, 91, 1860-1868.

Tybinka, A., Zaitsev, O., \& Blishch, G. (2016). Impact of autonomic tonus typological features on the duodenum structure of chickens. Veterinary MedicineOpen Journal, 1(1), 12-17.

Uesaka, T., Young, H. M., Pachnis, V., \& Enomoto, H. (2016). Development of the intrinsic and extrinsic innervation of the gut. Developmental Biology, 417, 158-167.

Uni, Z., Ganot, S., \& Sklan, D. (1998). Posthatch development of mucosal function in the broiler small intestine. Poultry Science, 77(1), 75-82

Uni, Z., Tako, E., Gal-Garber, O., \& Sklan, D. (2003). Morphological, molecular, and functional changes in the chicken small intestine of the late-term embryo. Poultry Science, 82, 1747-1754.

Varasteh, S., Braber, S., Akbari, P., Garssen, J., \& Fink-Gremmels, J. (2015). Differences in susceptibility to heat stress along the chicken intestine and the protective effects of galacto-oligosaccharides. PLoS One, 10(9), e0172511.

Verdal, H., Mignon-Grasteau, S., Jeulin, C., Le Bihan-Duval, E., Leconte, M., Mallet, S., Martin, C., \& Narcy, A. (2010). Digestive tract measurements and histological adaptation in broiler lines divergently selected for digestive efficiency. Poulty Science, 89, 1955-1961.

Wali, O. N., \& Kadhim, K. K. (2014). Histomorphological comparison of proventriculus and small intestine of heavy and light line pre- and at hatching. International Journal of Animal and Veterinary Advances, 6(1), 40-47.
Wang, F., Zuo, Z., Chen, K., Gao, C., Yang, Z., Zhao, S., Li, J., Song, H., Peng, X Fang, J., Cui, H., Ouyang, P., Zhou, Y., Shu, G., \& Jing, B. (2018). Histopathological injuries, ultrastructural changes, and depressed TLR expression in the small intestine of broiler chickens with aflatoxin B1. Toxins, 10(4), 131-147.

Wijtten, P. J. A., Langhout, D. J., \& Verstegen, M. W. A. (2012). Small intestine development in chicks after hatch and in pigs around the time of weaning and its relation with nutrition: A review. Acta agriculturae Scandinavica, A 62, 1-12.

Yamauchi, K. (2002). Review on chicken intestinal villus histological alterations related with intestinal function. The Journal of Poultry Science, 39(4), 229-242.

Yamauchi, K. (2007). Review of a histological intestinal approach to assessing the intestinal function in chickens and pigs. Animal Science Journal, 78, 356-370.

Yamauchi, K. E., Incharoen, T., \& Yamauchi, K. (2010). The relationship between intestinal histology and function as shown by compensatory enlargement of remnant villi after midgut resection in chickens. The anatomical record, 293(12), 2071-2079.

Yang, P., Gandahi, J. A., Zhang, Q., Zhang, L. L., Bian, X. G., Wu, L., Liu, Y., \& Chen, Q. S. (2013). Quantitative changes of nitrergic neurons during postnatal development of chicken myenteric plexus. Journal of Zhejiang University-Science B (Biomedicine and Biotechnology), 14(10), 886-895.

Yegani, M., \& Korver, D. R. (2008). Factors affecting intestinal health in poultry. Poultry Science, 87(10), 2052-2063.

Zeng, Y.-J., Qiao, A.-K., Yu, J.-D., Zhao, J.-B., Liao, D.-H., Xu, X.-H., \& Gregersen, H. (2003). Collagen fiber angle in the submucosa of small intestine and its application in gastroenterology. World Journal of Gastroenterology, 9(4), 804-807. 